\title{
Free Enterprise: Contributions of the Approach and Landing Test (ALT) Program to the Development of the Space Shuttle Orbiter
}

\author{
Peter W. Merlin ${ }^{*}$ \\ Analytical Services and Materials, Inc., NASA Dryden Flight Research Center, Edwards, CA, 93523
}

\begin{abstract}
The space shuttle orbiter was the first spacecraft designed with the aerodynamic characteristics and in-atmosphere handling qualities of a conventional airplane. In order to evaluate the orbiter's flight control systems and subsonic handling characteristics, a series of flight tests were undertaken at NASA Dryden Flight Research Center in 1977. A modified Boeing 747 Shuttle Carrier Aircraft carried the Enterprise, a prototype orbiter, during eight captive tests to determine how well the two vehicles flew together and to test some of the orbiter's systems. The free-flight phase of the ALT program allowed shuttle pilots to explore the orbiter's low-speed flight and landing characteristics. The Enterprise provided realistic, in-flight simulations of how subsequent space shuttles would be flown at the end of an orbital mission. The fifth free flight, with the Enterprise landing on a concrete runway for the first time, revealed a problem with the space shuttle flight control system that made it susceptible to pilot-induced oscillation, a potentially dangerous control problem. Further research using various aircraft, particularly NASA Dryden's F-8 Digital-Fly-By-Wire testbed, led to correction of the problem before the first Orbital Test Flight.
\end{abstract}

\section{Nomenclature}

$\begin{array}{ll}\text { AFFTC } & =\text { Air Force Flight Test Center } \\ \text { ALT } & =\text { Approach and Landing Test } \\ \text { AOA } & =\text { angle-of-attack } \\ \text { c.g. } & =\text { center-of-gravity } \\ \text { DFBW } & =\text { Digital Fly-By-Wire } \\ \text { DFRC } & =\text { Dryden Flight Research Center } \\ \text { FF } & =\text { Free Flight } \\ g & =\text { gravity } \\ \text { JSC } & =\text { Johnson Space Center } \\ \text { KEAS } & =\text { knots equivalent airspeed } \\ \text { KSC } & =\text { Kennedy Space Center } \\ \text { MDD } & =\text { Mate/Demate Device } \\ \text { mS } & =\text { milliseconds } \\ \text { NASA } & =\text { National Aeronautics and Space Administration } \\ \text { OFT } & =\text { Orbital Flight Test } \\ \text { OV } & =\text { Orbiter Vehicle } \\ \text { PIO } & =\text { pilot-induced oscillation } \\ \text { SCA } & =\text { Shuttle Carrier Aircraft } \\ \text { STS } & =\text { Space Transportation System } \\ \text { TIFS } & =\text { Total In-Flight Simulator }\end{array}$

\footnotetext{
${ }^{*}$ Historian/Archivist, NASA Dryden History Office, P.O. Box 273, Edwards, CA 93523
} 


\section{Approach and Landing Test - Risks vs. Benefits}

The space shuttle orbiter was the first spacecraft designed with the aerodynamic characteristics and inatmosphere handling qualities of a conventional airplane. In order to evaluate the orbiter's aerodynamic flight control systems and subsonic handling characteristics, a series of flight tests known as the Approach and Landing Test (ALT) program, were undertaken at NASA Dryden Flight Research Center (DFRC), Edwards Air Force Base, Calif., in 1977. The ALT program demonstrated the capability of the orbiter to safely approach and land under conditions simulating those planned for the final phases of an orbital flight.

The ALT program was managed by NASA's Johnson Space Center (JSC), Houston, Texas, while the test flights were conducted at DFRC and the Air Force Flight Test Center (AFFTC). The Edwards test site was selected because it included an instrumented test range with an extensive safety buffer zone and a 44-square-mile dry lakebed capable of supporting the landing weight of the orbiter. Lakebed runways were used for the first four landings while the fifth ended on a $15,000-\mathrm{ft}(4,570-\mathrm{m})$ concrete runway.

\section{A. Aircraft and Crews}

A full-scale orbiter vehicle prototype, named Enterprise and designated OV-101, was built for the ALT. With a length of $122 \mathrm{ft}(37.2 \mathrm{~m})$, wingspan of $78 \mathrm{ft}(23.8 \mathrm{~m})$, and a weight of 150,000 lb (68,000 kg) it was comparable in size and weight to a commercial transport aircraft. The majority of the orbiter's structure was made of aluminum alloys. Since it wouldn't be subjected to reentry heating, OV-101 was not covered with the space shuttle's reusable surface insulation. It was instead covered with other materials, primarily polyurethane foam and fiberglass, in order to maintain the mold lines for aerodynamic purposes. The flight deck consisted of two crew stations for the commander (left side) and pilot (right side) with displays and controls allowing a single crewman, operating from either station, to land the vehicle.

Aerodynamic controls included a body flap at the aft end, wing elevons and a split rudder that doubled as a speed brake. Reaction control systems, unnecessary at low altitude, were not installed. For the captive flights and the first three free flights an aerodynamic fairing covered the orbiter's aft end. On the last two flights, three dummy main engines were installed to simulate weight and aerodynamic characteristics of the operational orbiter.

The vehicle was designed with a planned landing speed of about $185 \mathrm{kn}(343 \mathrm{~km} / \mathrm{hr})$. It could be landed manually or by computer. The autoland system allows the computer to guide the orbiter to the runway by determining its heading and speed using the inertial navigation system, microwave scanning beam landing system, and other data sources.

A Boeing 747 was modified as a Shuttle Carrier Aircraft (SCA) to carry Enterprise to altitude for the captive and free-flight tests (Fig. 1). Most of the passenger accommodations were removed and parts of the fuselage underwent structural reinforcement to support the weight of the orbiter. Tip fins were added to the horizontal stabilizers. An emergency escape system slideway was provided for the $747 \mathrm{crew}$ (OV-101 was equipped with ejection seats) along with pyrotechnics to open an escape hatch in the side of the fuselage. Support struts (two aft and one forward) were installed atop the 747's fuselage to hold the orbiter. At the beginning of each free-flight, explosive bolts released the orbiter from the SCA.

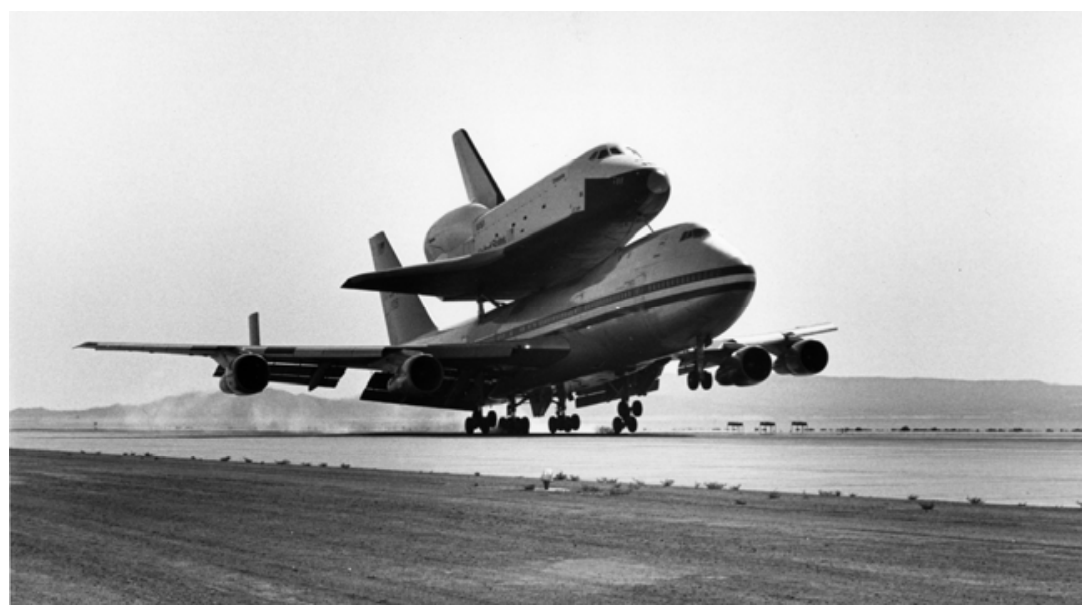

Figure 1. Shuttle Carrier Aircraft and orbiter in mated configuration. 
For captive-inert flights, DFRC personnel performed real-time flight control functions from one of the Dryden control rooms. Flight controllers at JSC were responsible for those flights during which the orbiter was manned. The captive-active and free-flight tests were coordinated from Mission Control in Houston.

NASA selected two two-man orbiter crews for the ALT. The first consisted of Fred W. Haise Jr. (commander) and C. Gordon Fullerton (pilot). The second consisted of Joe H. Engle (commander) and Richard H. Truly (pilot).

Crewmembers for the 747 SCA included pilots Fitzhugh L. Fulton Jr. and Thomas C. McMurtry and flight engineers Victor W. Horton, Thomas E. Guidry Jr., William R. Young, and Vincent A. Alvarez. ${ }^{1}$

While the SCA/orbiter combination did not constitute the first time one aircraft had been carried atop, and launched from, another it was by far the largest and heaviest combination to be used in such attempts. Some wags referred to the mated duo as the "world's largest biplane." 2

There were a number of risk factors. NASA engineers were concerned the tip plates on the SCA horizontal stabilizers, along with turbulence from the orbiter's aft end, would create excessive loads on the SCA tail. The orbiter was fitted with an aerodynamic tailcone to reduce buffeting on the SCA vertical tail, but the cone had to be removed for the final flights in order to study the aerodynamics of the orbiter's operational configuration. Removing the tailcone would reduce the orbiter's lift-to-drag ratio, thereby changing its flight characteristics. SCA/orbiter separation maneuvers were carefully planned to avoid a collision between the two vehicles. The two flight crews had to perform in a highly integrated fashion.

\section{B. The Value of Flight-Test}

Prior to the ALT engineers conducted wind-tunnel model tests and manned simulations, and made computational predictions for the performance of the two airplanes. The results gave planners confidence that the SCA and orbiter crews could safely perform the separation maneuver. Investigations showed that, because of the orbiter's angle-of-attack (AOA), an initial relative normal load factor of more than $1 \mathrm{~g}$ was attainable for the vehicle's entire gross-weight. In other words, the orbiter had positive lift while attached to the SCA, so the two airplanes were found to separate intrinsically. The orbiter tended to climb and fly straight up relative to the SCA and the 747 tended to descend mildly as the crew idled the engines and deployed spoilers, allowing the orbiter to clear the SCA tail in about 1.5 seconds. $^{3}$

The potential value of the ALT program outweighed the challenges and risks. From the beginning the flights were considered justified on the basis of the need to conduct a complete operational check of the orbiter's systems. The ALT flights also allowed for accurate flight calibration of the orbiter's air data system and, especially during the tailcone-off flights, provided accurate lift/drag data. Most important, the ALT program would provide experience that could not be gained from wind-tunnel tests or simulation. It would give the crews hands-on experience and familiarize the pilots with the cockpit systems and the "procedural aspects of landing under conditions that are much easier to control than on the Orbital Flight Tests (OFT)." ${ }^{4}$

\section{Flight-Testing the Orbiter}

The ALT program consisted of a series of incremental steps leading up to a final free flight demonstrating the orbiter's capability to land on a paved runway under conditions similar to those anticipated at the end of an orbital mission.

The first phase of the program involved airworthiness and performance verification of the modified 747 . Along with structural modifications made to accommodate the orbiter, the airplane's engines had been uprated to the JT9D-7AH configuration, a standard change available for airline operations. This allowed the use of rated takeoff thrust in flight for a maximum of 20 minutes. $^{5}$

The next step consisted of three taxi tests on the main runway at Edwards. NASA engineers were concerned about SCA landing gear taxi loads due to high center-of-gravity and heavy gross weight in ferry condition. ${ }^{6}$ Technicians instrumented the SCA nose gear for measurement of vertical, drag and side loads at the axle. Engineers also wanted to study buffeting of the SCA vertical tail at near takeoff speeds. Excessive buffeting could lead to fatigue damage, limiting the useful life of the SCA for ferry operations. The DFRC aerostructures team found calibrated strain gage measurements valuable in detecting critical tail loads and taxi turn limitations, verifying launch incidence and elevon settings, and monitoring empennage buffet.

OV-101 was placed atop the SCA at DFRC using a specialized crane called the Mate/Demate Device (MDD) (Fig. 2). On February 15, 1977, three taxi runs were accomplished at maximum speeds of 78, 122 and 137 knots. The SCA test team evaluated techniques for setting takeoff thrust, directional stability and control, elevator effectiveness, pitch response, thrust-reverser effectiveness, and airframe buffet. They found no areas of concern that would prevent proceeding with flight tests. ${ }^{7}$ 


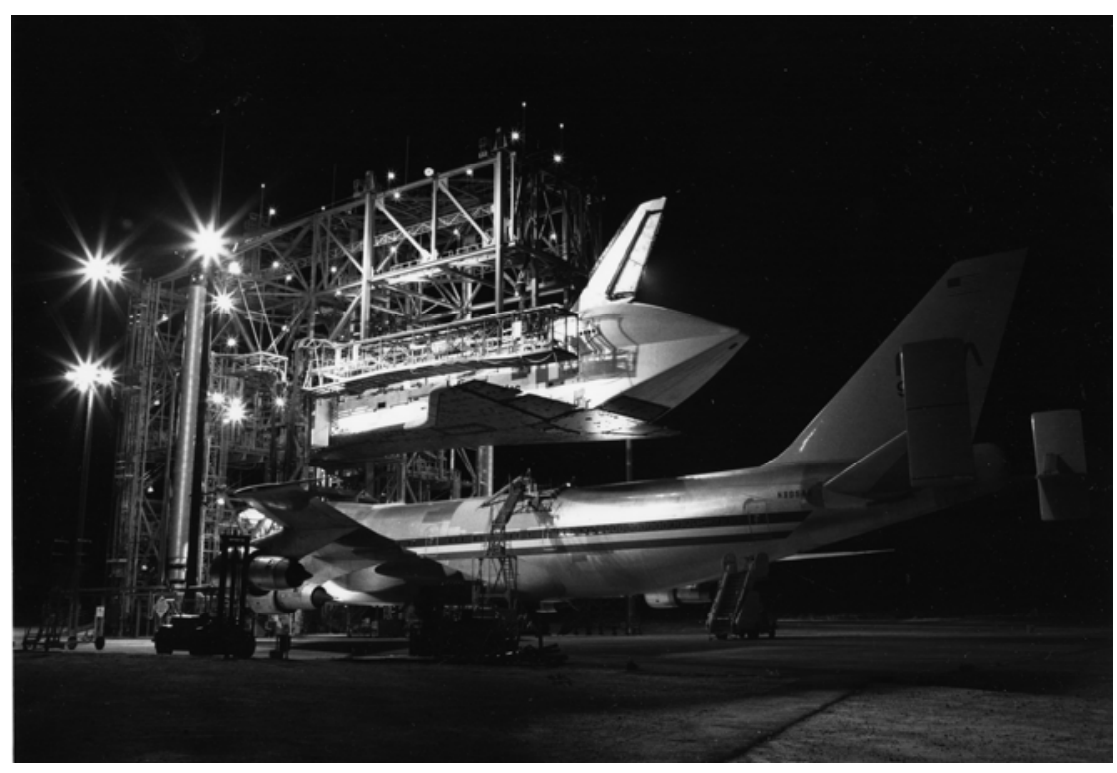

Figure 2. The orbiter is lowered onto the SCA in the Mate/Demate Device.

\section{A. Captive-Flight Tests}

Taxi tests were followed by five captive flights with an inert, unmanned orbiter to verify the airworthiness of the 747 as an orbiter transport vehicle and to establish an operational flight envelope for ALT operations. ${ }^{8}$ These flights provided data on flutter margins, empennage loads during maneuvers, buffet resulting from the mated configuration and the effects of SCA/orbiter longitudinal trim modifications. NASA engineers also wanted to verify interface loads and corresponding flight conditions to ensure positive launch separation and launch-abort maneuvers.

The first four captive-inert flights evaluated the mated configuration's airworthiness and established the operational flight envelope for subsequent captive-active and launch phases of the ALT program. The final captiveinert flight was devoted to flying two simulated launch profiles. The SCA crew successfully demonstrated that the 747 had the necessary performance capabilities to climb to the desired altitude and accomplish the launch maneuver at the desired separation parameters. The flights also demonstrated that the SCA crew could safely return to base with the orbiter if a launch was aborted.

In the captive-active phase the orbiter was powered up and manned while mated to the SCA. In consideration of the crew's safety, provisions were made for separation of the orbiter in the event of emergency. Three flights were conducted, to verify the separation profile as well as orbiter stability and performance in the mated configuration with combined operation of the primary flight control system, auxiliary power units, hydraulics and structure. Orbiter vertical-tail buffet data obtained during speed brake and rudder operation at $180 \mathrm{kn}$ indicated no significant adverse oscillations. Flutter clearance tests, performed during the second flight at speeds up to $270 \mathrm{kn}$, revealed no sustained vibrations. The orbiter's dynamic response to rapid control inputs from both the orbiter and SCA was highly damped and considered satisfactory. Tail buffet was measured at incremental speed brake settings and various rudder deflections resulting in structural responses that were well within limits. An autoland fly-through allowed the orbiter crew to verify that the attitude indicator and horizontal situation indicator displayed accurate indications. The landing gear was lowered to verify that it functioned properly (Fig. 3).

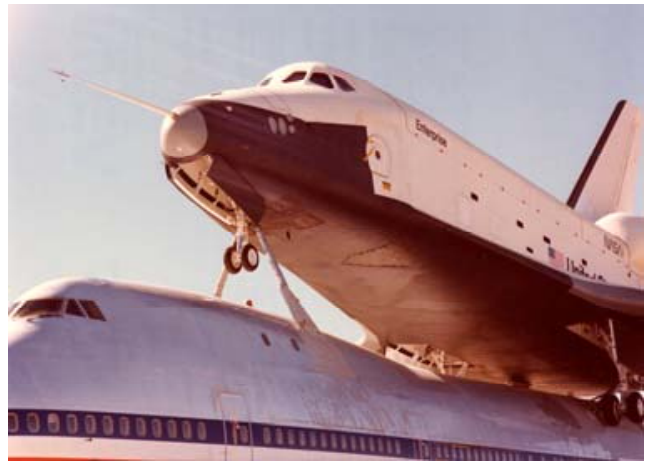

Figure 3. The orbiter's landing gear was lowered during the final captive-active flight.

Data from the second and third flights demonstrated that the operational separation profile and procedures were satisfactory for the first planned free flight. The captive-active flights also demonstrated the orbiter's hardware and software met the ALT requirements, and that support operations including turnaround, mission control and mission evaluation were satisfactory. 


\section{B. Free Flights}

The final phase of the ALT program included five free flights in which that orbiter was released from the SCA and glided to a landing at Edwards. The tests demonstrated the capability of the orbiter to safely approach and land on a runway in a variety of center-of-gravity (c.g.) configurations within the operational flight envelope. The first four flights ended on airstrips marked on the dry lakebed. The final flight concluded with touchdown on a concrete runway in order to obtain data on tire/pavement interface and qualify the deceleration system. For all flights, OV-101 was ballasted as a lightweight orbiter with a gross landing weight of approximately 150,000 pounds.

During the first three flights Enterprise flew with the tailcone on and with two different c.g. configurations. These were based on a pitch static-margin equivalency for the tailcone-off configuration and a flight control system test requirement to have a c.g. spread of 2 percent of the reference body length. Engineers knew a forward c.g. resulted in a more stable static margin (the difference between the vehicle's center-of-lift and center-of-gravity). The two final free flights, with the tailcone removed and replaced with dummy shuttle main engines, were conducted with the c.g. at 66.25 percent to simulate the planned c.g. for the initial orbital flight test.

The first free flight, on August 12, 1977, began with orbiter separation from the SCA at an altitude of about 22,800 ft above ground level at 270 knots equivalent airspeed (KEAS) (Fig. 4). Haise and Fullerton executed two 90 percent left turns during descent (Fig. 5) and landed on lakebed runway 17 five minutes and 22 seconds after separation. Touchdown was approximately a mile beyond the predicted landing point. The crew performed steering, braking, and coasting tests during the 11,000-ft rollout.

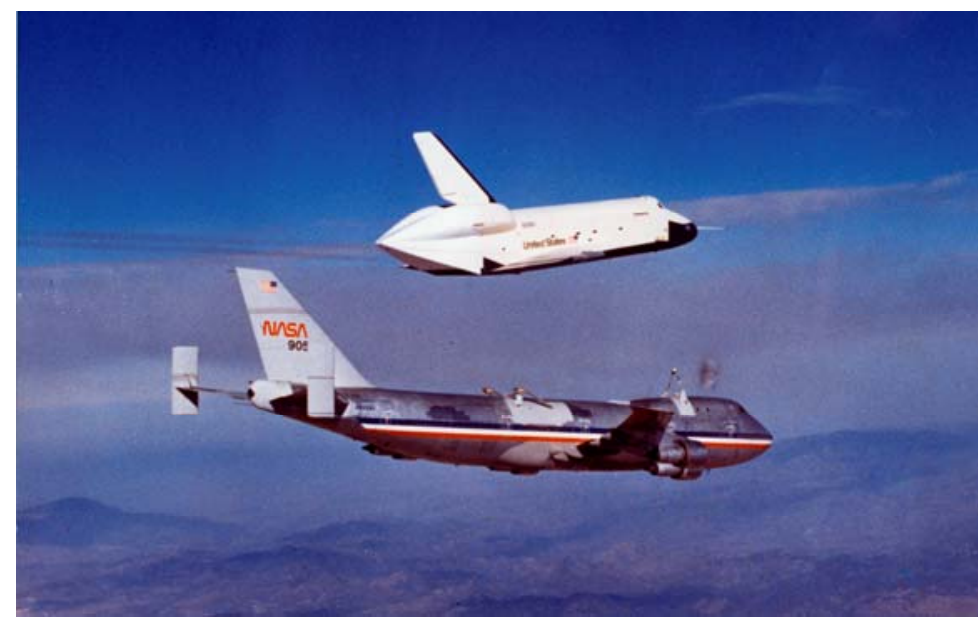

Figure 4. The orbiter separates from the SCA during the first free-flight.

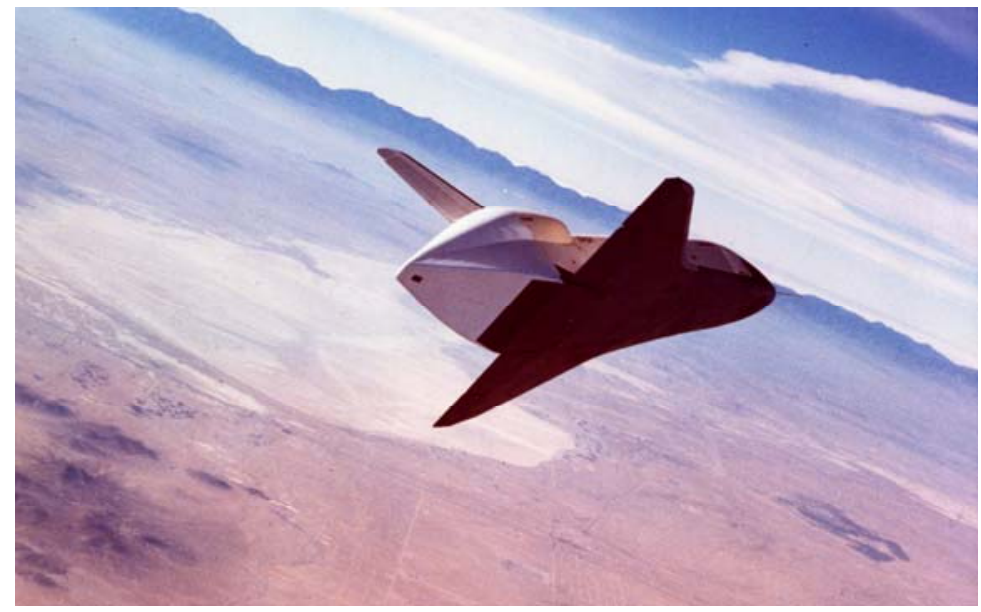

Figure 5. The orbiter approaches the lakebed landing site. 
Separation for Free Flight 2 (FF-2), piloted by Engle and Truly (the crews alternated for each flight), occurred at an airspeed of 270 KEAS and an altitude of 23,200 feet. The crew performed a 1.8- $g$ wind-up turn of about 135 deg and another 45 deg left turn. They completed various programmed stick inputs for flight control system and structural evaluation. Following five minutes and $31 \mathrm{sec}$ of free flight, Enterprise touched down on runway 15 (Fig. 6). The landing point was $680 \mathrm{ft}$ beyond the predicted touchdown and rollout was 10,037 feet. During heavy, moderate, and differential brake application a "chattering" phenomenon was experienced as the natural frequency of the gear struts resonated with the anti-skid control gains.

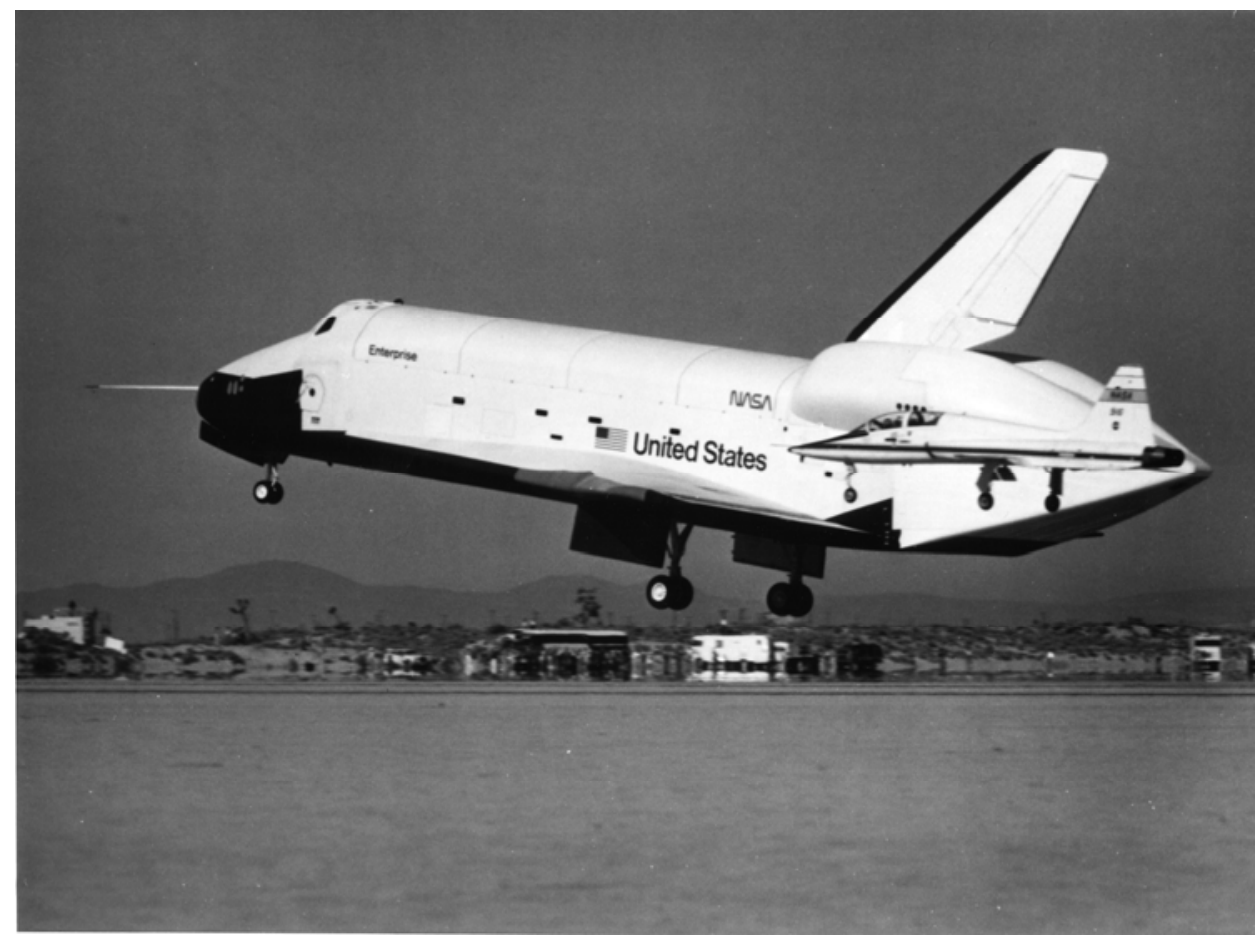

Figure 6. The orbiter, accompanied by a chase plane, just prior to touchdown on the lakebed runway.

The orbiter's c.g. was moved aft from 63.8 percent to 65.8 percent of the reference body length for FF-3 to simulate tailcone-off stability characteristics at 67 percent. Separation from the SCA was initiated at 250 KEAS and 24,100 feet. The crew accomplished wind-up turns of 140 percent and 40 percent and performed test inputs and aerodynamic stick inputs as on the previous flight. Closed-loop automatic guidance was employed after the final turn and Enterprise landed on runway 17 with five minutes and 35 seconds of flight time. Touchdown was $786 \mathrm{ft}$ beyond the predicted point and rollout was 9,147 feet. After coasting for $23 \mathrm{sec}$, the crew applied gentle to moderate differential braking commencing at a speed of about 150 knots. When hard braking was applied at low speeds (from 115 to $20 \mathrm{kn}$ ), the chattering effect was again detected. This low-frequency vibration was so violent that pilot Gordon Fullerton later commented, "I thought we were going to shake the wings off." Nose wheel touchdown took place 3,489 ft after main gear touchdown and the crew engaged nose wheel steering at a speed of 12 knots. Following the flight, engineers developed changes to the anti-skid system in order to eliminate the brake chatter problem.

FF-4 was the first tailcone-off flight (Fig. 7). The SCA crew flew two circuits of a racetrack pattern, extending about $70 \mathrm{mi}$ from Edwards, in order to gather flightworthiness and buffet data. The special-rated-thrust modification was engaged to gain additional altitude for separation. The orbiter was separated at a speed of 245 KEAS and an altitude of 17,700 feet. During the two-minute-and-35-second glide flight the orbiter crew performed an angle-of-attack sweep and aerodynamic stick inputs to collect data on performance, stability and control, and flight handling qualities. Only two turns of 10 deg each were made for the purpose of aligning with runway 17. Enterprise touched down $510 \mathrm{ft}$ beyond its planned landing point and rolled 5,725 feet. The crew performed braking and nose wheel steering tests during the landing roll and encountered no brake chatter. 


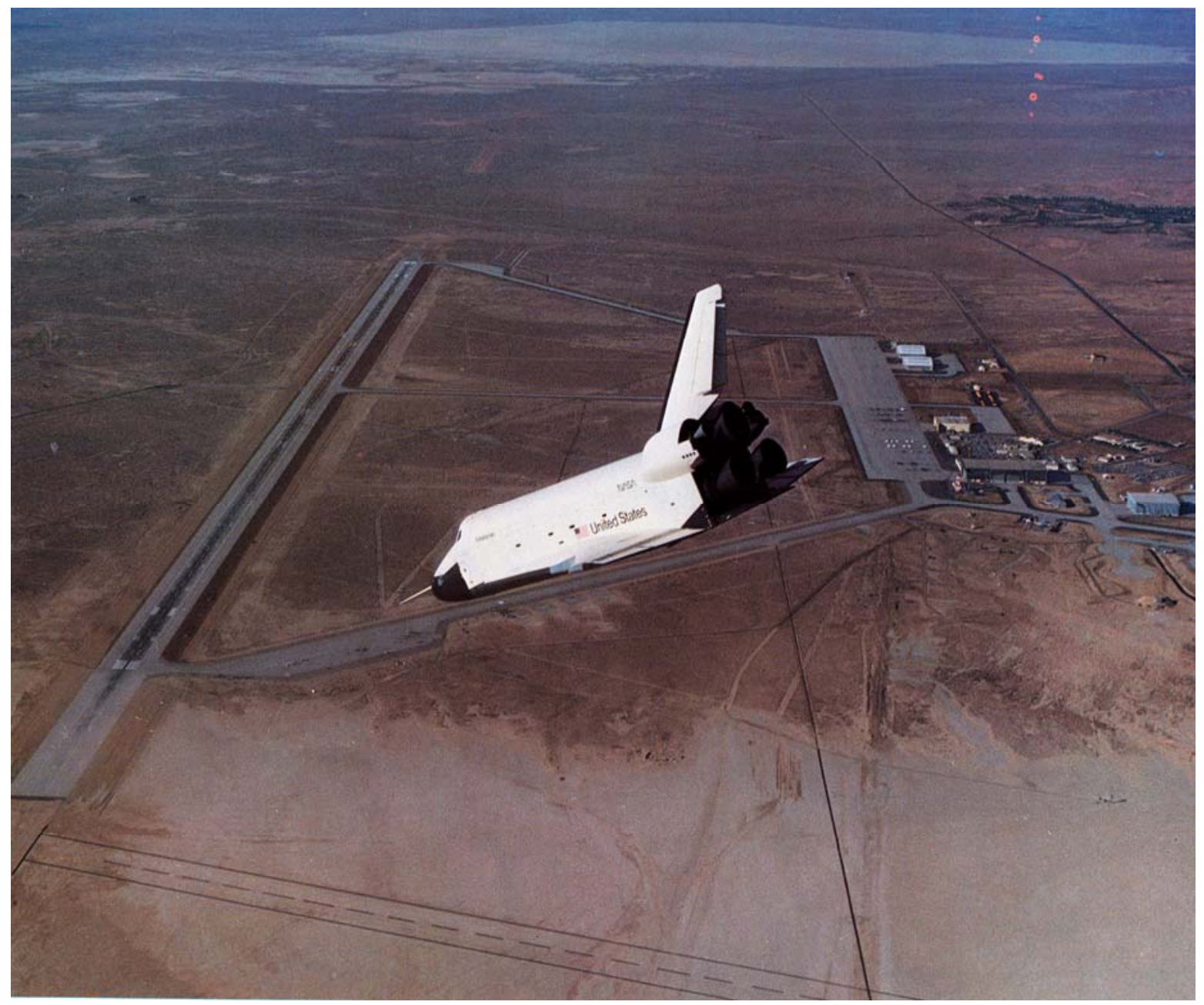

Figure 7. The orbiter during the first tailcone-off free-flight, with the Edwards main runway in the background.

Separation for FF-5 was accomplished at an airspeed 245 KEAS and altitude of 17,000 feet. The orbiter made a straight-in approach to runway 04 , the 15,000 -ft concrete airstrip with a lakebed overrun. The crew controlled the entire approach and landing sequence manually. ${ }^{\dagger}$ During the final eight seconds prior to touchdown the pilot's control inputs to control sink rate caused an unexpected pitch oscillation. The control system software limited the elevon rate to $26 \mathrm{deg} / \mathrm{sec}$ in order to cope with hydraulic flow limits for the elevon actuators. Because the system was designed to give priority to pitch inputs, the flight control system failed to respond quickly to some roll inputs. This resulted in four seconds of pilot-induced oscillation (PIO) as the orbiter touched down (Fig. 8) gently with wings level and then skipped back into the air while rolling to the right. The pilot ceased roll input momentarily, allowing the motion to damp out immediately prior to a second touchdown six seconds after the first. The left wheel bounced momentarily but the vehicle quickly settled into a normal rollout. After nose wheel touchdown the crew applied light braking until the orbiter decelerated to $100 \mathrm{kn}$, heavy braking down to $50 \mathrm{kn}$, and finally light braking again until the vehicle came to a stop. The first main gear touchdown occurred 1,000 ft beyond the planned touchdown point and the final touchdown was $1,900 \mathrm{ft}$ further. Total runway rollout distance from the initial touchdown was 7,930 feet. $^{9}$

${ }^{\dagger}$ Each crew station is equipped with identical rotational hand controllers. In pitch, the controller pivots about the palm of the hand; in roll, it pivots about a point slightly below the base. The two controllers are not mechanically linked, but if both are deflected the input signals are combined and the elevons respond accordingly. 


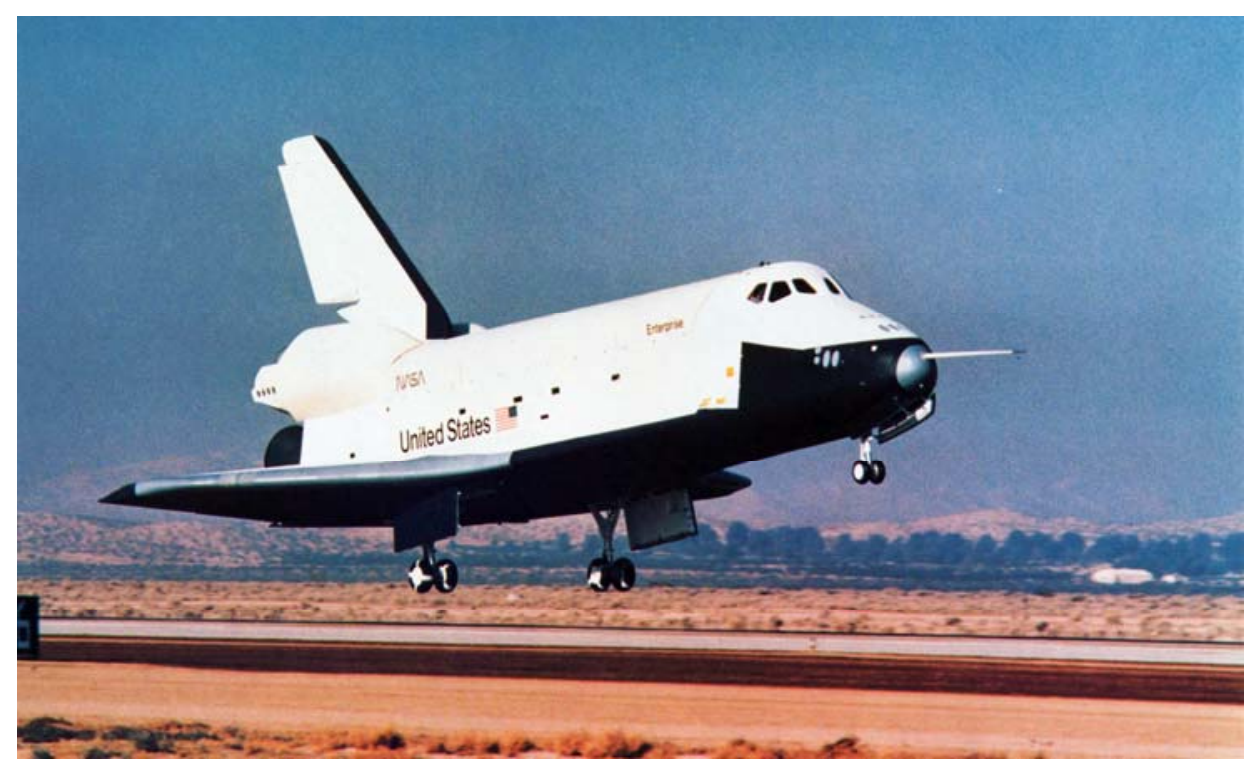

Figure 8. The final free-flight ended with a landing on the concrete main runway at Edwards.

\section{Pilot-Induced Oscillation - Problem and Solutions}

Throughout the free-flight series the orbiter performed well mechanically and structurally. With and without the tailcone, the ALT tests verified preflight aerodynamic predictions. Perhaps most significant, the final free flight revealed the orbiter's susceptibility to PIO, prompting NASA engineers to develop a way to fix the problem before the first Orbital Flight Test.

\section{A. Runway Dance}

As Enterprise approached the Edwards main runway (Fig. 9), the pilot adjusted the vehicle's attitude in order to increase airspeed to 290 knots. Meanwhile the commander made left rudder and roll inputs prior to speed brake deployment to complete a set of aerodynamic data requirements. Enterprise intercepted the glideslope at 9,600 ft above ground level while the crew maintained alignment with the surface aim point and correlated instrument readings. In a smooth transition, as the orbiter dropped through 7,000 ft, the commander assumed control of the speed brake. When Enterprise was 4,000 ft above ground level, the crew noticed that they had drifted above the

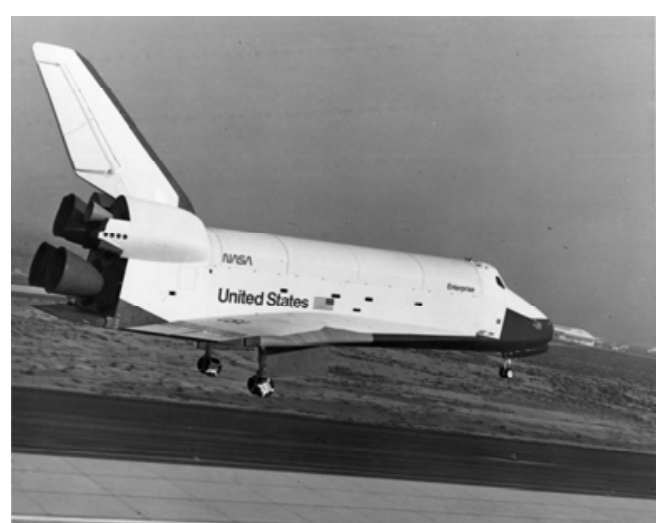

Figure 9. Enterprise approaches the concrete runway as the crew adjusts the approach attitude. glideslope. To reacquire the aimpoint and prevent overspeed, the commander pitched the nose over and deployed speed brakes to 80 percent. He responded to a momentary 10-kn airspeed decrease by reducing speed brakes slightly. The pilot then noted an airspeed decrease to $275 \mathrm{kn}$ followed by a rapid increase to 290 knots.

At 2,000 $\mathrm{ft}$ above the ground, the orbiter was on a slightly steep trajectory but still aligned with the aimpoint. Indicated airspeed was $294 \mathrm{kn}$ (four knots higher than planned) and the orbiter was $600 \mathrm{ft}$ closer to the runway threshold than planned. The commander delayed speed brake retraction to compensate for the excess speed, but there was a seven-knot tailwind. As the crew lowered the landing gear, Enterprise approached the runway threshold at the correct altitude but $20 \mathrm{kn}$ faster than planned. The commander set the speed brakes to 50 percent, anticipating that the vehicle would be slow at touchdown, but it continued to remain high at $200 \mathrm{kn}$ as it approached within $500 \mathrm{ft}$ of the touchdown line. 
The orbiter seemed to float at an altitude of four ft. The commander attempted to overcome this with forward rotational hand-controller commands with no effect. The orbiter's altitude then ballooned slightly before touching down smoothly some $1,000 \mathrm{ft}$ beyond the planned point and at a speed of 180 knots. Enterprise skipped upward into the air and rolled to the right. As the pilot attempted to level the wings, a lateral PIO developed. As the oscillations continued the crew realized the roll commands through the rotational hand controller were abnormally large while control response was lagging. The pilot discontinued command inputs and allowed the roll rate to damp out to nearly wings-level.

About six seconds after skipping into the air, Enterprise touched down for a second time. The crew was forced to accept a higher-than-normal sink rate because of concern about airspeed bleedoff to 155 knots. Consequently the orbiter landed harder than planned. The left main wheel also lifted slightly on the rebound but quickly settled onto the runway. The crew fully opened the speed brakes and applied differential braking to bring the orbiter to a stop. ${ }^{10}$

\section{B. Analyzing the Problem}

Analysis of the data from Free Flight 5 indicated the PIO resulted from control stick inputs entered during the last eight seconds prior to initial touchdown. Pilot inputs to control sink rate resulted in large elevon motion (12 deg peak-to-peak) at $0.6 \mathrm{~Hz}$ and kept the elevons rate-limited throughout most of the touchdown sequence. This overrotation caused the orbiter to skip back into the air. The pilot was unaware of any problem beyond the fact that he was landing long. He applied a forward stick input to halt the ballooning and inadvertently initiated a roll command, possibly due to the unusual control stick geometry (stick longitudinal axis is inclined to the vehicle's axis). Because the center of pitch motion is near the cockpit, normal acceleration cues were lacking during small pitch oscillations. Also, due to cockpit visibility limitations, small changes in pitch attitude were not readily apparent to the crew. Consequently neither crewmember detected the oscillation that caused elevon rate limiting. ${ }^{11}$

The pilot attempted to correct the roll motion and applied forward stick to force the orbiter back down to the runway. This combination of control inputs saturated the control system, allowing phase lag to build up as the pilot continued to overcontrol in both pitch (to re-establish flight path control) and roll (as a result of PIO). Because of the rate-saturated pitch channel, the flight control system's priority rate-limiting design did not allow response to some roll inputs. Because pitch had priority, the hydraulic system priority logic locked out any roll commands. This triggered the large roll delay at touchdown and subsequent PIO. By releasing the controller momentarily the pilot allowed the motions to damp out naturally just prior to the second touchdown. ${ }^{12}$

Engineers at DFRC launched an all-out effort to comprehend and solve the orbiter's PIO problem. In early 1978 Milton O. Thompson, director of Dryden's Research Projects branch, drafted a plan to "obtain a current data base that will sharpen our awareness of all factors (subtle and obvious) that might influence a low L/D [lift-to-drag] orbiter runway landing in demanding situations.” Part of the program called for application of ALT data to computerized simulators for the purpose of familiarizing shuttle pilots with the gain settings for landing. At the same time Dryden's F-8 Digital Fly-By-Wire (DFBW) testbed - an ex-Navy fighter jet with highly modified flight controls - provided flight-test data to determine how delayed computer response to human input might be reduced or eliminated. ${ }^{13}$

The F-8 DFBW aircraft (Fig. 10) had been modified in the 1970s with a digital flight control system. The pilot could select predetermined values for various flight parameters using an input keypad linked to an AP-101 computer that had been used on one of the Apollo lunar missions. The airplane was not inherently prone to PIO so in order to evaluate a PIO suppression filter, it was necessary to implement a programmed time delay in the control system. The pilot was given the ability to activate and deactivate the control delay as necessary. ${ }^{14}$

Five research pilots flew PIO data flights resulting in 60 landings simulating the orbiter's control characteristics. They found that lags as short as $200 \mathrm{~ms}$ between pilot input and discernible control surface response profoundly impacted the aircraft's handling qualities. At the PIO condition, rate limiting decreased system gain and introduced phase lag into the system. ${ }^{15}$

The solution was development of a software filter that dampened the types of pilot inputs most likely to cause oscillations, without affecting handling qualities or causing control time delays. These software changes worked, reducing PIO tendencies. Greater landing control, however, came at the expense of some degree of control-stick responsiveness. ${ }^{16}$

Additional studies were carried out in 1978 using the Air Force's Calspan Total In-Flight Simulator (TIFS) (Fig.11), a highly modified C-131H transport aircraft. The results characterized deficiencies in the orbiter's lowaltitude longitudinal handling qualities contributing to the pilot's inability to precisely control flight-path angle and altitude change rate, predict aircraft response to control inputs, and adequately control the vehicle in disturbances due to external forces such as wind gusts. ${ }^{17}$ 


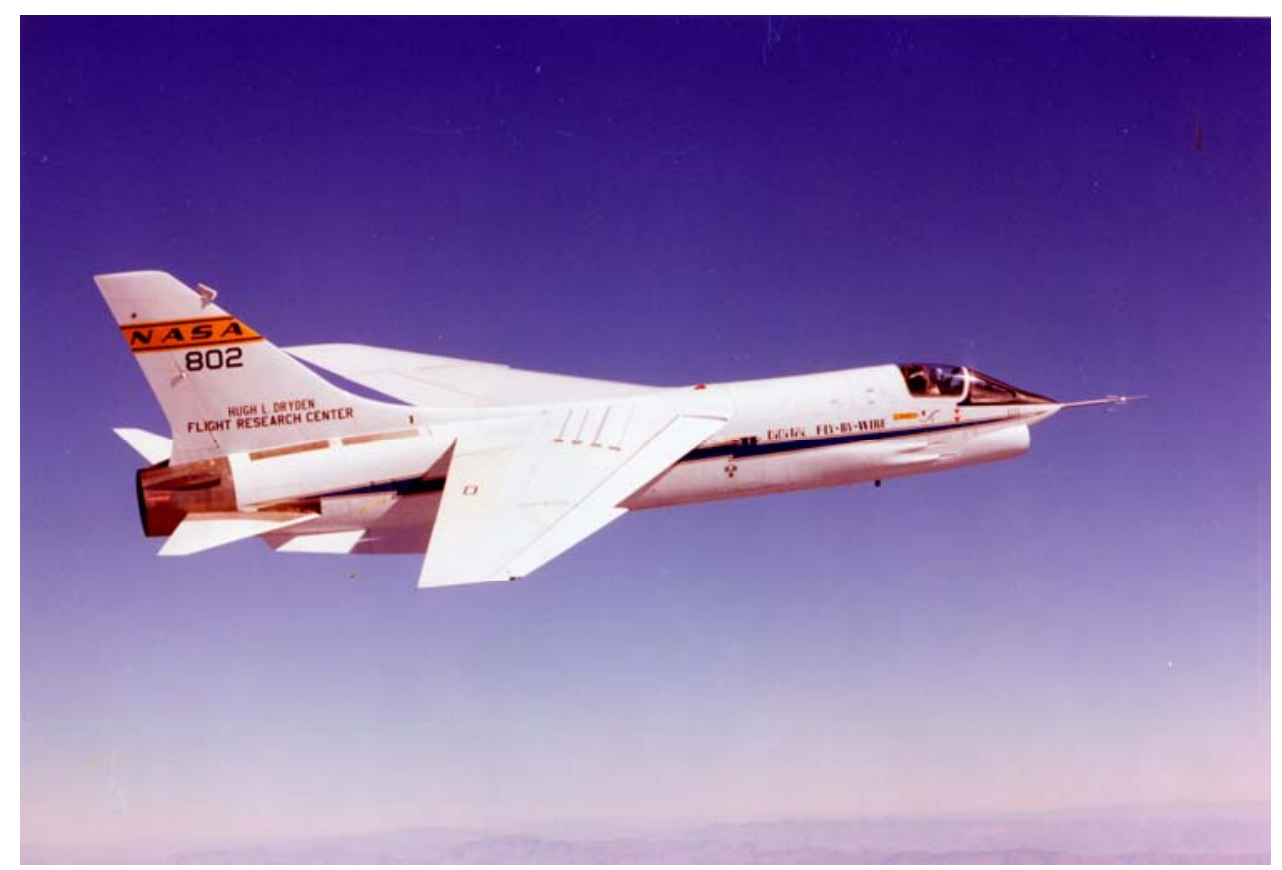

Figure 10. F-8 Digital Fly-By-Wire testbed.

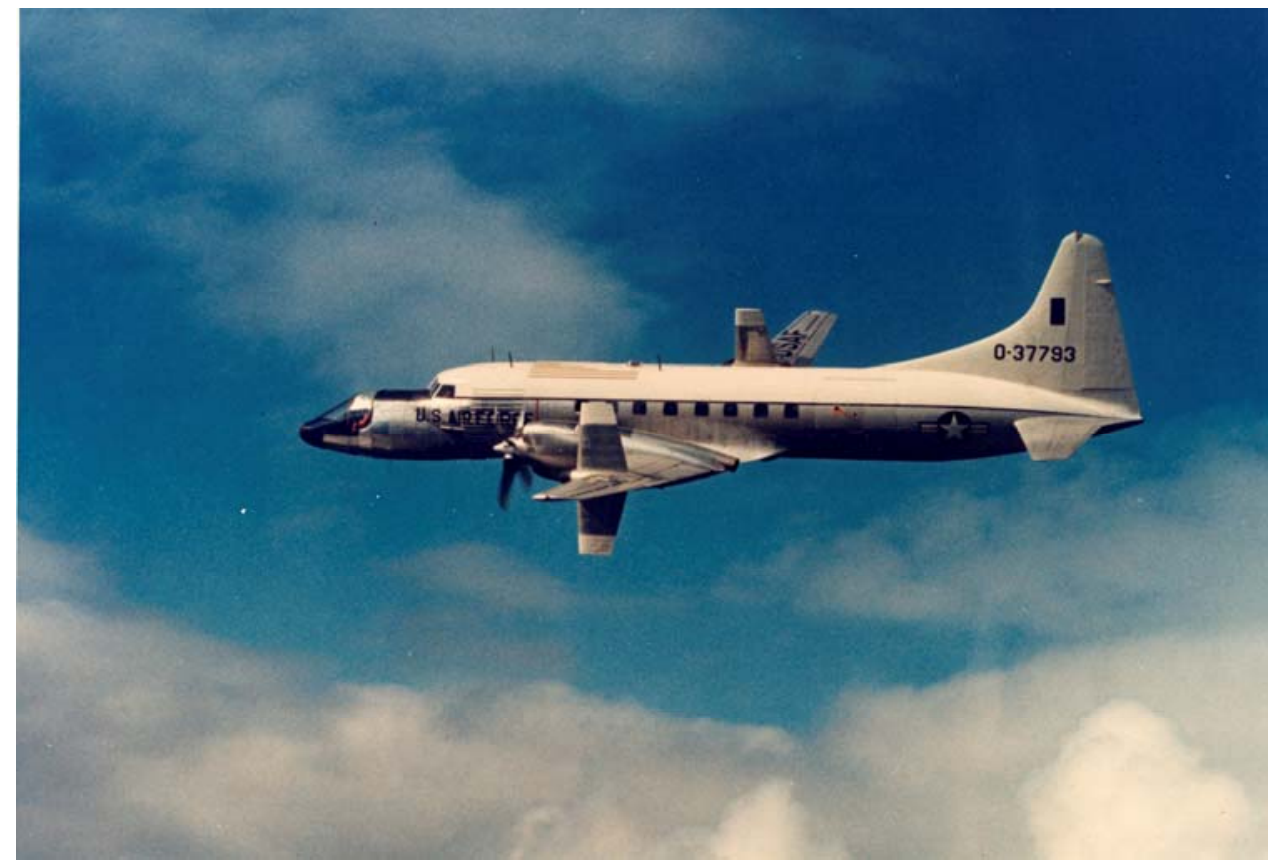

Figure 11. NC-131H Total In-Flight Simulator. 
The objective of the TIFS flight research was to evaluate orbiter handling qualities with various proposed mechanizations of the FCS. The flight-test program was designed to replicate the ALT FF-5 flight control problem and develop control system modifications for incorporation into the OFT orbiter Columbia (OV-102). A series of flights was planned to first replicate the ALT FF- 5 conditions then simulate a nominal OFT- 1 baseline configuration and variations of OFT-1 with alternative transport lag, surface rate limit, and forward-loop pitch gain. Other variables included use of a conventional stick controller and simulation of a cockpit moved $40 \mathrm{ft}$ further forward. ${ }^{18}$

Eight NASA research pilots (including five shuttle astronauts) flew 16 two-hour flights in the TIFS. They completed 155 approaches (78 actual and 77 simulated). Flight conditions included both actual and simulated air turbulence. ${ }^{19}$

A model-following accuracy and test technique developed during the TIFS simulations provided useful data for assessment of pilot performance in potentially off-nominal situations. The primary evaluation pilots (one each from DFRC and JSC) successfully performed simulated and actual touchdowns in the OFT-1 baseline configuration for all tasks investigated. Only 15 percent of the approaches received satisfactory handling qualities ratings from the pilots. Of the rest, 70 percent were rated unsatisfactory and the remaining 15 percent were considered unacceptable due to the orbiter's unforgiving longitudinal control characteristics. Pilots with minimal or no prior experience with orbiter flight simulations had severe difficulty achieving successful landings due to inability to perceive deviations and make desired corrections to the flight path quickly enough. With extreme concentration, more experienced pilots found it easier to perceive deviations and avoid the need for large flight-path corrections. Additionally, they were able to develop a pulsing control technique to minimize rate-limiting problems. ${ }^{20}$

The orbiter's PIO tendencies were found to be considerably more noticeable in flight tests than in ground simulations. Based on the level of their experience, the TIFS evaluation pilots decided they desired a well damped, but more responsive, airplane. This goal was achieved, to some degree, by increasing the pitch forward-loop gain and allowing unlimited elevon surface rates. Some evaluation pilots noted improved handling qualities when the cockpit was "moved" $40 \mathrm{ft}$ forward of the center of pitch-rotation. Additionally, the conventional center stick provided improved control compared to the rotational hand controller. ${ }^{21}$

Using data obtained from fixed-base and in-flight simulations, NASA engineers developed reasonably effective PIO suppression filters for use on OFT-1. Because the software revisions merely mitigated, but did not completely eliminate, the orbiter's latent PIO tendencies, scientists at DFRC continued to study the problem well into the 1980s (well after the first orbital test flights).

\section{Lessons Learned and OFT Results}

Development of the space shuttle orbiter produced the first reusable spacecraft capable of returning from orbit and landing on a conventional runway. This bold, pioneering effort forced engineers to confront complex challenges in developing a vehicle with longitudinal flying qualities required for landing the orbiter manually in an operational environment. The ALT program was the final hurdle before the first orbital mission.

Based on ALT flight data and orbiter crew evaluations, all objectives of the program were successfully accomplished. The orbiter's aerodynamic performance and loads were as predicted by wind-tunnel testing and computer analysis. During FF-5 the orbiter's roll response was found to be less than expected due to rate limiting, leading to follow-on research to correct the PIO problem. To improve chances of coping with deviations at landing (i.e. turbulence and crosswinds), the Approach and Landing Evaluation Team at JSC recommended the following:

1) The [orbiter's] energy state should be maintained at the preplanned nominal level throughout the flight trajectory using standardized pilot techniques or autoland.

2) The trajectory from preflare to touchdown should be optimized for manual control.

3) Operational and flight control system limits should be determined and verified by simulation to determine the crew and vehicle capabilities and limitations to perform a safe landing.

4) The FCS must be modified to always provide at least some combination of pitch and roll capability to allow manual and automatic control for landing.

5) The FCS sensitivity to PIO should be reduced.

6) Nominal trajectory planning should not require the use of speed brakes after flare. ${ }^{22}$

Engineers determined the orbiter had two modes affecting longitudinal control. The first involved the effective time delay between pilot input and vehicle response in pitch attitude control. As on most aircraft the mechanical control actuators contribute a significant delay, as do structural and smoothing filters required because of the highgain feedback control system. The digital flight control system also contributes delays because of the average sampling time and computation time. A nonlinear control stick gearing provided good sensitivity around the neutral 
stick position while retaining a good maximum pitch rate or normal acceleration capability, but contributed to the orbiter's pitch attitude PIO tendencies.

The second mode is altitude or flight path control. Loss of lift caused by elevon deflection causes a nose-up pitch command to result in a downward acceleration at the center of gravity. Because the cockpit is near the center of rotation there is a 0.5 -sec delay before the pilot detects the motion. The sluggish rise time of the acceleration to its steady-state value, combined with delayed perception of motion, makes it difficult for the pilot to accurately control attitude. High cockpit location and poor forward visibility also contribute to the pilot's inability to judge both attitude and altitude near touchdown. ${ }^{23}$

The PIO suppression filter designed following the DFBW and TIFS investigations was added to the orbiter's flight control system software prior to OFT-1/STS-1 (originally scheduled for 1979, but later slipped to April 1981). Although the filter virtually eliminated high-frequency PIO tendencies, it was not designed to improve lowfrequency, large-amplitude heave mode characteristics near touchdown produced by poor flight path control. Nevertheless, orbiter crews had no significant high-frequency PIO problems during the first 12 OFT landings. Extensive simulator training for orbiter pilots prevented all but a few isolated incidents of overcontrol tendencies in the subsonic longitudinal axis during the OFT and subsequent operational missions. Autoland was used on STS-3 (the third OFT flight) all the way through the landing flare. The pilot then took over for manual landing and experienced a hard touchdown because he perceived and reacted to a "heave mode" (positive pitch change) that had not, in fact, occurred. ${ }^{24}$

As director of Dryden's Research Projects branch and an experienced research pilot, Milt Thompson had reservations about the orbiter's flying qualities. He admitted that the software changes offered improvements in the orbiter's handling qualities and safety but still felt that problems with the vehicle's flight control system existed and needed to be resolved. In late 1980, just a few months before Columbia's maiden flight, Thompson shared his feelings with a colleague at JSC:

I would improve the landing control system as soon as possible. Real handling quality improvements in the landing control system would eliminate the need for the PIO training. The PIO suppressor does not improve the handling qualities during landing. The PIO suppressor is simply a crutch which does not address the real problem. I do not feel the entry handling qualities are as good as they should be...[and] should be improved before the Shuttle becomes operational. ${ }^{25}$

Prior to OFT-1, however, NASA officials concluded the orbiter could safely fly at subsonic speeds down to landing. Flight research and analysis had verified that the handling qualities were sufficiently understood and that the crew could accomplish a safe return from orbit. For their exceptional efforts, the four Enterprise crewmen received the Kincheloe Award from the Society of Experimental Test Pilots. ${ }^{26}$

The orbiter Columbia (OV-102) launched into space for the first time on April 12, 1981. After completing a twoday orbital checkout the crew, John Young and Robert Crippen, made a successful landing on the Edwards dry lakebed (Fig. 12). The orbiter performed flawlessly, ushering in a new era in space transportation. Several more orbital flight test missions were conducted before the space shuttle was declared operational. The operational orbiter fleet expanded to include Challenger (OV-099), Discovery (OV-103), and Atlantis (OV-104). Enterprise (OV-101) continued to serve as a ground-based testbed for structural dynamics and fit-check verification tests. After the loss of Challenger in 1986 a replacement orbiter, Endeavour (OV-105), was built.

An analysis of flight-test results from the first 12 orbital shuttle missions by the AFFTC Office of Advanced Manned Vehicles concluded, "Presently, the Orbiter's insidious subsonic longitudinal handling qualities are considered acceptable considering the scope of the current STS program which relies heavily upon the skills of a relatively small and specially trained crew of astronauts." Air Force analysts felt the orbiter's handling difficulties were the result of vehicle configuration design rather than control system deficiencies. They recommended that future spacecraft designers conduct simulator investigations on the effects of cockpit location with respect to the longitudinal center of rotation of the vehicle. ${ }^{27}$

Over the course of 25 years the space shuttle fleet has accomplished 113 successful landings from orbit. Of these, 50 took place at Edwards (17 on the lakebed and 33 on the concrete runway). One mission, STS-3, ended with a landing at Northrup Strip (now White Sands Space Harbor), N.M. The remaining 63 landings took place at Kennedy Space Center (KSC), on Merritt Island near Titusville, Fla. A total of 20 landings (six at Edwards and 14 at KSC) took place at night. Without question the ALT program paved the way for this remarkable record of achievement. 


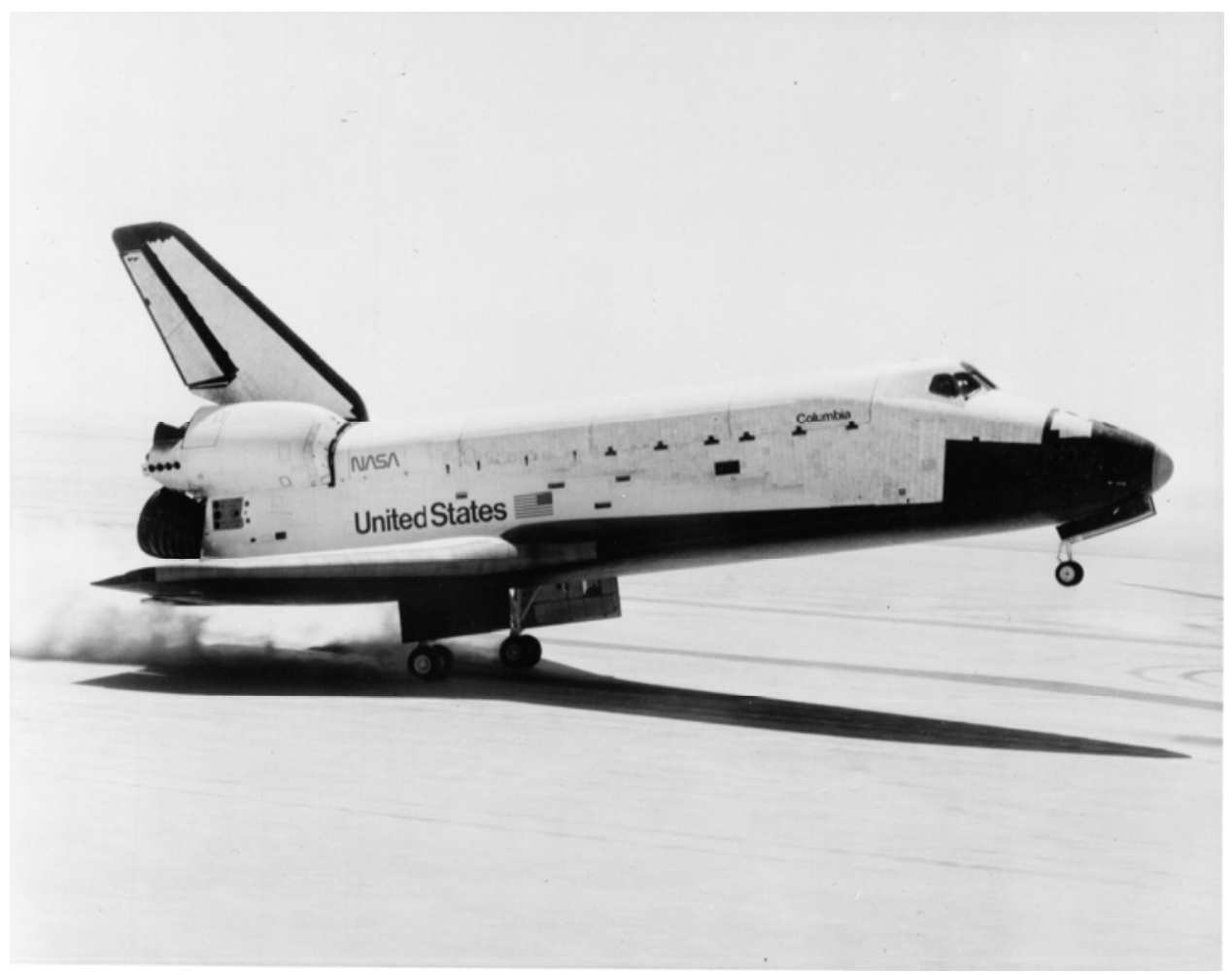

Figure 12. Columbia lands at Edwards following the first orbital flight-test.

\section{Acknowledgments}

The author wishes to acknowledge C. Gordon Fullerton for taking the time to review the original draft of this paper and educate the author on space shuttle orbiter flight control systems. Special thanks to Dryden X-Press assistant editor Sarah Merlin, AS\&M, Inc., for proofreading my work and Debbie Phillips for assisting with the layout.

\section{References}

\footnotetext{
1 “Press Kit: Space Shuttle Orbiter Test Flight Series,” Release No. 77-16, National Aeronautics and Space Administration, Washington, D.C., Feb. 4, 1977.

${ }^{2}$ Hallion, R. P., and Gorn, M. H., On The Frontier: Experimental Flight at NASA Dryden, Smithsonian Books, Washington, D.C., 2003, p. 237.

${ }^{3}$ Pope, H. A., “ALT Manned Simulations - Orbiter/747 Separation,” NASA JSC Engineering Analysis Division briefing, Houston, TX, Jan. 20, 1975 (in the NASA DFRC Historical Reference Collection, File Folder L1-5-2-7, files of Milton O. Thompson).

${ }^{4}$ Rediess, H. A., memorandum to DFRC Shuttle Projects Manager from Director of Research re. Assessment of ALT Tests with Tailcone On vs. Off, NASA DFRC, Edwards, CA, March 17, 1976 (in the NASA DFRC Historical Reference Collection, File Folder L2-1-3C-6, Space Shuttle files).

${ }^{5}$ Hoey, R. G., et al., "AFFTC Evaluation of the Space Shuttle Orbiter and Carrier Aircraft - NASA Approach and Landing Test,” AFFTC-TR-78-14, Office of Advanced Manned Vehicles, Edwards, CA, May 1978.

${ }^{6}$ Carter, A. L., deputy chief, Aerostructures Division, memorandum to Milton O. Thompson, chief engineer re. Review of Shuttle carrier Aircraft (SCA) Structural Issues, July 13, 1977 (in the NASA DFRC Historical Reference Collection, File Folder L2-1-3A-2, Space Shuttle files).

7 Approach and Landing Test Evaluation Team, "Space Shuttle Orbiter Approach and Landing Test - Final Evaluation Report,” JSC-13864, NASA JSC, Houston, TX, Feb. 1978.

8 Andrews, W. H., "Space Shuttle Orbiter Approach \& Landing Test - Mated Inert Flight Test Plan," NASA DFRC, Edwards, CA, Jan. 28, 1977.
} 


\footnotetext{
9 “Space Shuttle Orbiter Approach and Landing Test - Final Evaluation Report,” JSC-13864.

10 ibid.

11 ibid.

${ }^{12}$ Thompson. M. O., notes on "Sequence of events on FF-5 landing," n.d. (in the NASA DFRC Historical Reference
} Collection, File Folder L1-5-2-2, Milton O. Thompson Collection).

${ }^{13}$ Gorn, M. H., Expanding the Envelope: Flight Research at NACA and NASA, The University Press of Kentucky, Lexington, KY, 2001, Chap. 8, p. 351.

${ }^{14}$ Shafer, M. F., Smith, R. E., Stewart, J. F., and Bailey, R. E., "Flight Test Experience with Pilot-Induced Oscillation Suppression Filters,” NASA TM 86028, Jan. 1984.

${ }^{15}$ Smith, J. W., "Analysis of a Longitudinal Pilot-Induced Oscillation Experienced on the Approach and landing Test of the Space Shuttle,” NASA TM-81366, Dec. 1981.

${ }_{16}^{16}$ Gorn, M. H., Expanding the Envelope, Chap. 8, pp. 352-353.

${ }^{17}$ Hoey, R. G., et al., "Flight Test Results from the Entry and Landing of the Space Shuttle Orbiter for the First Twelve Orbital Flights,” AFFTC-TR-85-11, Office of Advanced Manned Vehicles, Edwards, CA, June 1985.

${ }^{18}$ Chalk, C. R., and Reynolds, P. A., "Test Plan - Simulation of Orbiter Landing Characteristics in the USAF Total In-Flight Simulator (TIFS),” Calspan Corporation, TIFS Memo No. 844, May 25, 1978.

19 “TIFS Program Summary,” n.d. (in the NASA DFRC Historical Reference Collection, File Folder L1-5-2-2, Milton O. Thompson Collection).

20 "DFRC Orbiter Landing Investigation Team Final Presentation,” Aug. 1978 (in the NASA DFRC Historical Reference Collection, File Folder L1-5-7-22, Milton O. Thompson Collection).

${ }^{21}$ ibid.

${ }^{22}$ JSC-13864.

${ }^{23}$ Powers, B. G., “Low-Speed Longitudinal Orbiter Flying Qualities,” Space Shuttle Technical Conference, NASA CP-2342, Part 1, Johnson Space Center, Houston, TX, 1983, pp. 143-150.

${ }^{24}$ Hoey, et al., AFFTC-TR-85-11, and comments of C. Gordon Fullerton while reviewing a draft of this paper.

${ }^{25}$ Gorn, M. H., Expanding the Envelope: Flight Research at NACA and NASA, The University Press of Kentucky, Lexington, KY, 2001, Chap. 8, pp. 353-354.

${ }^{26}$ Hallion, R. P., Test Pilots: The Frontiersmen of Flight, Smithsonian Institution Press, Washington, D.C., 1981 , p. 274.

${ }^{27}$ Hoey, R. G., et al., "Flight Test Results from the Entry and Landing of the Space Shuttle Orbiter for the First Twelve Orbital Flights,” AFFTC-TR-85-11, Office of Advanced Manned Vehicles, Edwards, CA, June 1985. 